\section{BADN EXTENDS DEADLINE FOR AWARD NOMINATIONS}

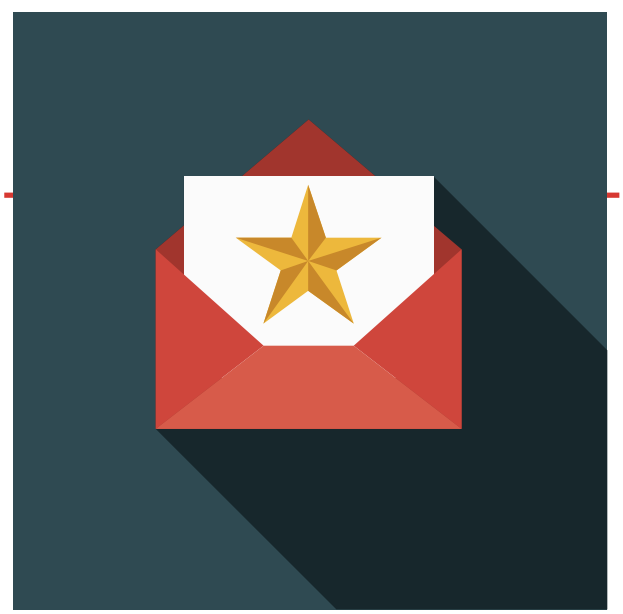

The British Association of Dental Nurses (BADN), the UK's professional association for dental nurses, is extending its deadline for nominations for BADN's four awards until 30 March 2020.

\section{Award for Outstanding Service to Dental Nursing Professional Practice}

This is awarded to a person with a minimum of ten years' service in the dental nursing profession who has made an outstanding contribution to the development and/or support of the dental nursing profession. That contribution should be to dental nursing as a whole, not to the nominee's specific workplace; have had a notable impact either UK-wide or across one of the home countries (England, Scotland, Wales or Northern Ireland); and have been to the benefit of the dental nursing profession generally, not just to a specific sector.

\section{Award for Exceptional}

Commitment as a Dental Nurse Student

This is awarded to a person who has made an exceptional commitment to their own progression and personal professional development whilst studying for either a registerable dental nursing qualification, a post-registration or extended duties qualification, or a qualification at a higher academic level (eg an MSc or BSc, etc).

The commitment should have had a notable impact on the student's personal professional development and should have demonstrated an exceptional application to their programme of study to achieve their own personal professional goals, in addition to having demonstrated a personal professional behaviour throughout the course of study.

The nominee must have studied in one of the home countries (England, Scotland, Wales, Northern Ireland), and their study must have been to the benefit of the dental nursing profession generally, not just a specific sector.
Award for Exceptional Service to Dental Charities

This is awarded to a person who has made an exceptional contribution to one of the dental charities. That contribution should be to a dental charity as a volunteer, in order to promote the charity's aims and objectives, and to have impacted upon the nominee's personal professional development. The contribution should have had a notable impact nationally or internationally and have benefitted those in genuine need of oral health interventions.

\section{Award for Exceptional}

\section{Contribution to a UK Community} Oral Healthcare Project

This is awarded to a person who had made an exceptional contribution to one of their local UK Community Oral Healthcare projects. That contribution should be to a UK community oral healthcare project as a volunteer to promote the project's aims and objectives and to have impacted upon the nominee's personal professional development. The contribution should have had a notable impact locally and have benefitted those in genuine need of oral health interventions.

All nominees must be current BADN members and, with the exception of the Student Award where applicable, be GDC Registered Dental Nurses.

Full Guidelines and application forms are available on the BADN website www.badn. org.uk or from events@badn.org.uk.

BADN Chair Jane Dalgarno said: 'We want to encourage dental nurses to nominate themselves or a dental nurse colleague so that we can recognise the enormous contribution made by dental nurses to dentistry. However, we recognise that people have had other things on holiday period, and so are extending the deadline to the end of March'.

The Awards will be presented at the BADN's 80th Anniversary Afternoon Tea at the NEC Hilton on Saturday 16 May 2020. their minds over the Christmas/New Year

\section{'Gin in a tin' sugar content exposed in survey}

A new product survey conducted by Action on Sugar has shown that popular 'ready to drink' pre-mixed spirits and cocktails sold in supermarkets are extremely high in hidden sugar and calories.

To mark Sugar Awareness Week in January, Action on Sugar called on the new government to ensure that all alcoholic drinks are included in vital public health policies, and said that major UK retailers should be forced to reformulate their pre-mixed alcoholic drinks to the agreed criterion set by government in the Soft Drinks Industry Levy (SDIL) or pay the fine.

Some of the beverages surveyed contained nine teaspoons of sugar in just $250 \mathrm{ml}$ (as well as alcohol) and nine out of ten pre-mixed spirits did not have on-pack sugar information.

WKD Blue contained $59 \mathrm{~g}$ of sugar in a $700 \mathrm{ml}$ bottle - the equivalent of eating over four iced doughnuts in one sitting. Classic Combinations Pink Gin and Tonic contained $27 \mathrm{~g}$ of sugar in a $250 \mathrm{ml}$ can, the same sugar content as Coca Cola.

Katharine Jenner, Campaign Director at Action on Sugar, based at Queen Mary University of London, said: "'Gin in a tin" has become a cultural phenomenon with these types of drinks often consumed "on the go" and without a moment's consideration to how much sugar and alcohol goes into making them. Even if you did want to know, you can't make a healthy choice as only one in ten of the products surveyed had enough information available. If consumers knew how much sugar was really in these drinks, would they still happily choose to drink their way to tooth decay, obesity and type 2 diabetes?'

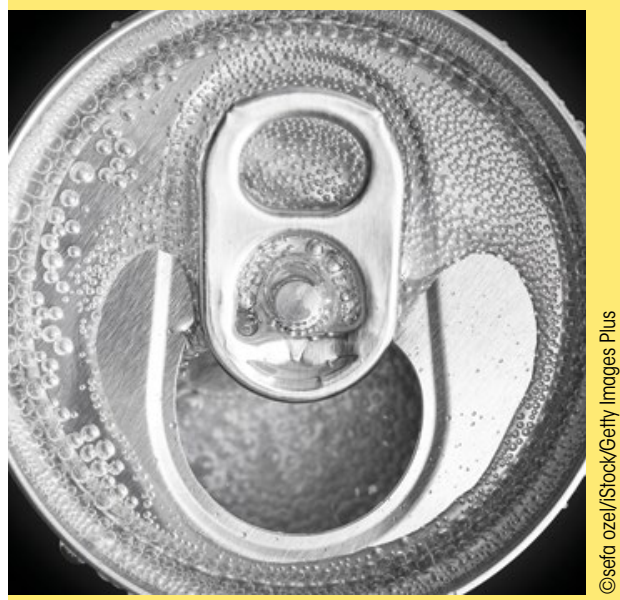

